HOMENAGEM

ANTONIO E. NARDI

JOSÉ C. APPOLINÁRIO

ANTONIO GERALDO DA SILVA

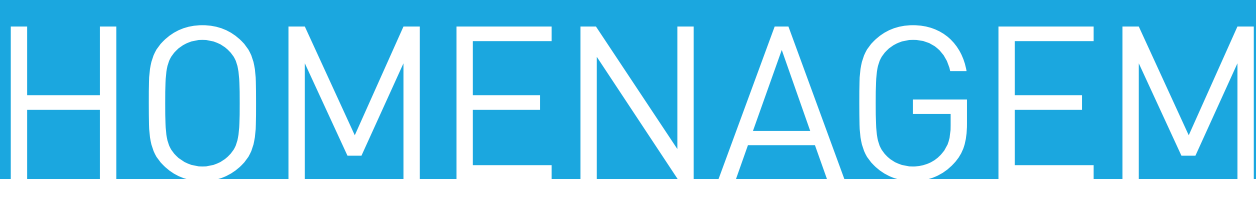

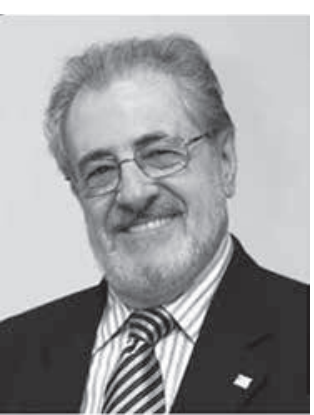

Professor João Romildo Fanucci Bueno 07/08/1938 - 17/08/2019

\title{
A TIRELESS RESEARCHER IN PSYCHOPHARMACOLOGY AND A GOLD-STANDARD PHILOSOPHER: THE SCIENTIST AND HUMANIST JOÃO ROMILDO BUENO (1938-2019)
}

A psiquiatria mundial - e a psiquiatria brasileira em particular - estão de luto. Perdemos um de nossos maiores professores e mais queridos amigos. $\bigcirc$ Professor João Romildo Fanucci Bueno nos deixou, mas suas aulas, suas histórias e seu conhecimento universal permanecerão em nossos corações e farão parte de nossas reuniões para sempre.

Em 17 de agosto de 2019, o Professor Romildo faleceu repentinamente, apenas 10 dias depois de seu $81^{\circ}$ aniversário. Ele se mantinha muito ativo até os últimos dias, dando continuidade a seu trabalho clínico e a seu papel de líder na vida associativa profissional da Associação Brasileira de Psiquiatria (ABP).

O Professor Romildo trilhou uma carreira longa e excepcional na psiquiatria, com um interesse especial pela psicofarmacologia, cobrindo as áreas de pesquisa, ensino e assistência, e servindo como principal mentor para várias gerações de psiquiatras brasileiros. Era

\footnotetext{
* Texto originalmente publicado em inglês no Brazilian Journal of Psychiatry, com a seguinte referência: Nardi AE, Appolinário JC, da Silva AG. A tireless researcher in psychopharmacology and a gold-standard philosopher: the scientist and humanist João Romildo Bueno (19382019). Braz J Psychiatry. 2019;41:378-9.
}

um homem muito perspicaz, reconhecido por seus conhecimentos gerais, que abarcavam vários aspectos da vida, e não apenas aqueles restritos à psiquiatria. Sua personalidade carismática se caracterizava pela curiosidade constante, pela postura desafiadora diante do status quo e pelo carinho que demostrava por todos, sempre levando no rosto um sorriso amigável.

Nascido em Cambuí, no estado de Minas Gerais, o Professor Romildo graduou-se em 1964 na Faculdade de Medicina da Universidade Federal do Rio de Janeiro (UFRJ) - a antiga Faculdade Nacional de Medicina. Interessado em psicofarmacologia já no início de sua carreira e sob a orientação do Professor Lauro Solero, um farmacologista brasileiro, ele recebeu uma bolsa de pesquisa do Conselho Nacional de Desenvolvimento Científico e Tecnológico (CNPq) para um estágio no Galesburg State Research Hospital, na cidade de Galesburg, Illinois, EUA, sob a supervisão do Professor Harold E. Himwich, um dos principais pesquisadores da época na área de psiquiatria biológica. Durante esse período, ele participou de investigações fundamentais sobre os mecanismos biológicos subjacentes aos transtornos mentais e completou sua formação como psiquiatra.

Ao retornar ao Brasil, em 1965, o Professor Romildo foi nomeado professor associado do Instituto de 
Psiquiatria da UFRJ, onde ocupou posteriormente vários cargos acadêmicos. Apenas para mencionar alguns, ele foi responsável pela disciplina de Psicofarmacologia no Programa de Pós-Graduação, participou da gestão geral do Instituto como ViceDiretor por mais de 15 anos e foi Editor-Chefe do Jornal Brasileiro de Psiquiatria por muitos anos. Além disso, o Professor Romildo foi chefe do Departamento de Psiquiatria e Medicina Legal da Faculdade de Medicina da UFRJ de 1990 a 1996. Em 1979, ele se tornou professor titular de Psiquiatria na mesma instituição, até sua aposentadoria, em 2005.

O Professor Romildo publicou mais de 100 artigos, capítulos de livro, revisões e trabalhos apresentados em congressos. Nos anos 1960, ele participou como autor principal de artigos de grande repercussão na área de psicofarmacologia da depressão ("A dualistic approach to some biochemical problems in endogenous depressions"1 ${ }^{\prime 1} \mathrm{e}$ da esquizofrenia ("Behavioral and biochemical alterations in schizophrenic patients"2). Dada a vastidão de seu interesse científico, suas publicações contemplaram uma ampla gama de assuntos no campo da psiquiatria ${ }^{3,4}$ inclusive adentrando outras áreas. ${ }^{5}$ Vale destacar que o professor Romildo participou como investigador nos programas de desenvolvimento de vários agentes psicofarmacológicos lançados nos últimos anos..$^{6,7}$ Durante o ano passado, ele esteve envolvido com muito entusiasmo em um estudo de longo prazo que acompanhou de perto por mais de duas décadas. ${ }^{8}$

Por fim, não podemos deixar de mencionar o papel fundamental exercido pelo Professor Romildo no desenvolvimento de nossa associação, a ABP, desde sua concepção. Foi Presidente da ABP entre 1983 e 1986, e foi seu Tesoureiro de 2010 a 2016. Atualmente ele ocupava o cargo de Editor Sênior no periódico Debates in Psychiatry, de Conselheiro Consultivo na Diretoria Executiva da ABP e de Diretor Secretário da Asociación Psiquiátrica de América Latina (APAL). Ademais, ele sempre foi muito ativo na sua estimada ABP e comparecia com satisfação a todas as reuniões.

Querido Romildo, os encontros da psiquiatria brasileira certamente não serão os mesmos sem a sua presença. Contudo, você sempre estará em nossas histórias e memórias. Onde quer que psiquiatras brasileiros se reúnam, você estará com eles.
Um grande professor e contador de histórias nunca morre. Você viverá para sempre em nossos corações.

Os autores informam não haver conflitos de interesse associados à publicação deste artigo.

Fontes de financiamento inexistentes.

Correspondência: Antonio Egidio Nardi. E-mail: antonioenardi@gmail.com

\section{Referências}

1. Bueno JR, Himwich HE. A dualistic approach to some biochemical problems in endogenous depressions. Psychosomatics. 1967;8:82-94.

2. Spaide J, Tanimukai H, Bueno JR, Himwich HE. Behavioral and biochemical alterations in schizophrenic patients. Arch Gen Psychiatry. 1968;18:658-65.

3. Bueno JR, Teixeira AR, Fernandes MF. An experimental evaluation of the anti-anxiety effects of some antidepressants. J Bras Psiquiatr. 1971;20:179-91.

4. Tanimukai H, Ginther R, Spaide J, Bueno JR, Himwich HE. Detection of psychotomimetic $\mathrm{N}, \mathrm{N}$-dimethylated indoleamines in the urine of four schizophrenic patients. Br J Psychiatry. 1970;117:421-30.

5. Appolinario JC, Bueno JR, Coutinho W. Psychotropic drugs in the treatment of obesity: what promise? CNS Drugs. 2004;18:629-51.

6. Versiani M, Bueno JR, Mundim FD, da Silva JA, Rocha AV. A double-blind comparison between loxapine and chlordiazepoxide in the treatment of neurotic anxiety. Curr Ther Res Clin Exp. 1976;20:701-15.

7. de Oliveira IR, Elkis H, Gattaz WF, Chaves A, de Sena EP, de Matos E Souza FG, et al. Aripiprazole for patients with schizophrenia and schizoaffective disorder: an open-label, randomized, study versus haloperidol. CNS Spectr. 2009;14:93-102.

8. Ferreira-Garcia R, da Rocha Freire RC, Appolinário JC, Levitan MN, Halkjær-Lassen RD, Bueno JR, et al. Tranylcypromine plus amitriptyline for electroconvulsive therapy-resistant depression: a long-term study. J Clin Psychopharmacol. 2018;38:502-4. 